\title{
Explanation in Points of the Aetiology of the So- Called Idiopathic Scoliosis (Adolescent Idiopathic Scoliosis [AIS])
}

ISSN: 2576-8875

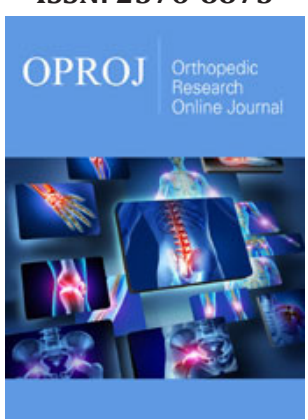

${ }^{* 1}$ Corresponding author: Tomasz Karski, Professor, Lecturer in Vincent Pol University in Lublin, Poland

Submission: 留 June 24, 2019

Published: 跰July 03, 2019

Volume 5 - Issue 5

How to cite this article: Tomasz $\mathrm{K}$. Explanation in Points of the Aetiology of the So-Called Idiopathic Scoliosis (Adolescent Idiopathic Scoliosis [AIS]). Ortho Res Online J. 5(5). OPROJ.000623.2019. DOI: 10.31031/OPROJ.2019.05.000623

Copyright@: Tomasz Karski, This article is distributed under the terms of the Creative Commons Attribution 4.0 International License, which permits unrestricted use and redistribution provided that the original author and source are credited.

\section{Tomasz Karski*}

Lecturer in Vincent Pol University in Lublin, Poland

\begin{abstract}
In the years 1984 to 2007 was described the biomechanical aetiology on the So-Called Idiopathic Scoliosis (Adolescent Idiopathic Scoliosis [AIS] [1-29]. The "biomechanical aetiology" explain asymmetries of movement of the right and the left hip, next - asymmetries of standing right: left leg - mostly on right and also connection with gait. Why gait - explanation - the maximally absent movements of right hip during every step are transmitted as "compensatory movement" to the pelvis and to the spine - causing the deformity rotation deformity. They are three group and four types of etiopathogenesis (epg) of scoliosis depending of three "model of hips movement" [7].
\end{abstract}

Keywords: Idiopathic scoliosis; Aetiology; Classification; Therapy; Prophylaxis

\section{Introduction}

To understand the presented theory of aetiology of the so-called idiopathic scoliosis is necessary to use the new tests in examination. Important is to check the hips movements - adduction in straight position of joints to understand the biomechanical influences "permanent standing 'at ease' on the right leg" and "gait".

\section{Material}

In the years 1984-2019 in Lublin research were examined 2500 patients with scoliosis. The control group was 340 children - presented by parents with the suspecting of scoliosis. In examination of these children it was full and symmetrical movement of hips and all tests no found the spine deformity.

\section{Explanation the questions concerning the etiology of scoliosis in points} (Literature [6-20])

The etiology is biomechanical: It is connected with the asymmetry of movements of the hips. These asymmetries are one of seven asymmetries in anatomy and in function described as the "Syndrome of Contractures" [SofC] - Prof. Hans Mau (Tubingen, Germany). From 2006 we speak in Lublin about "Syndrome of Contractures and Deformities" (SofCD) because I added to the seven changes in SofC the shank varus deformity in newborn and babies as the eight deformity. In 2006 was described the specific "model of hips movement" and depending of them the type of scoliosis.

Why do girls have more frequent scoliosis?: The SofCD exist mostly in girls. The asymmetries of hip movement appear more frequent in girls - they have more frequent scoliosis.

Why do we mostly observe the lumbar left convex curve?: The SofCD is mostly "left sided", it is limited adduction of the right hip, the standing 'at ease' on the right leg is easy, more stable and taken by many of people. Such standing after 8-10 years produces the lumbar left convex scoliosis.

Why do we mostly observe the thoracic right convex curve?: Permanent standing on the right leg - causes the lumbar left convex "C" scoliosis and if in a child exist in the same time the "laxity of the joints" also can appear a secondary right convex thoracic curve. 
Why is the rib hump (gibbous costalis) on the right side? The "rib hump" on the right side of thorax is connected with walking. This deformity appears in $1^{\text {st }}$ "S" epg, 3D, scoliosis and is connected with the "specific model of hips movement". The maximally limited movement of the right hips is, as "compensatory movement" transmitted by every step to the pelvis and spine and make rotation deformity. Due to rotation distortion in inter vertebral joints appears stiffness of the spine and gibbous.

When does scoliosis start to develop-in which year of the life of a child?: Every type of scoliosis starts to develop when the child starts to "stand" and starts to "walk". The "S" scoliosis in $1^{\text {st }}$ epg is to be seen at the age of 4-6 years, the " $\mathrm{C}$ " $2^{\text {nd }} / \mathrm{A}$ epg scoliosis and " $S$ " $2^{\text {nd }} / \mathrm{B}$ epg is to be seen at the age of 10-12 years.

What kind of classification is proper?: Biomechanical etiology explains present of three groups and four types of scoliosis. All groups in this "new classification" are connected with a "model of hip' movements" and function - gait and standing [7]:

A. $\quad 1^{\text {st }}$ epg - "S" scoliosis - 3D - two curves, stiff spine, gibbous on the right side of thorax. Connection with gait and with permanent standing 'at ease' on the right leg.

The first symptoms of oncoming scoliosis are rotation deformity especially in the region of Th6-Th12 and beginning of stiffness.

B. (2a) $2^{\text {nd }} / A$ "C" scoliosis - 1D - one curve - lumbar left sided - connection with permanent standing 'at ease' on the right leg,

C. (2b) $2^{\text {nd }} / \mathrm{B}$ "S" scoliosis - 1 or $2 \mathrm{D}$ - two curves. Connection with permanent standing 'at ease' on the right leg - plus laxity of joints and wrong and harmful previous treatment (!). In this both types the spine is flexible.

D. $\quad 3^{\text {rd }}$ epg "I" scoliosis - 1/2D - small curves or any, small gibbous or any - only stiffness of the spine. The $3^{\text {rd }}$ epg scoliosis is connected only with gait. Deformity appears after walking.

See-the children in Mongolia have no scoliosis (Prof. Jozsef Hyanek, Czech Republic-personally information), they mostly ride horses, exist - no or rare influence of "standing" and "walking".

Does a "primary curve" or "secondary curve" exist?: In "S" $1^{\text {st }}$ epg - both curves - lumbar left convex and thoracic - right convex appears et the same time. In "S" $2^{\text {nd }} / \mathrm{B}$ epg scoliosis the thoracic right convex curve appeared as secondary curve.

Why is there a rapid progression of scoliosis in the acceleration period of a child's growth?: Child's bone growth, the contracted soft tissue on the lateral side of the right hip does not grow and because of this the influence on development of the spine deformity is bigger.

Which type of scoliosis progresses?: The progression is especially in the " $S$ " $1{ }^{\text {st }}$ epg scoliosis.

Which type of scoliosis does not progress?: The scoliosis "C" in $2^{\text {nd }} /$ A type and "S" $2^{\text {nd }} / B$ epg, does not progress or not significantly. In scoliosis $3^{\text {rd }}$ epg, patients get to know about the problem in adulthood, because of pain.
What is meant by the worldwide use of the term "the natural history of scoliosis"?: Incorrect therapy - in result progression of scoliosis. Please - pay attention - in past - the etiology was not discovered - and the result because of wrong and improper therapy not good. Such bad result was described as "the natural history of scoliosis".

Why don't fully blind children have scoliosis?: The blind children walk without lifting their legs. Do not exist during gait the "compensatory movement of pelvis and spine" which elaborate scoliosis. The blind children have also the habit to stand carefully on both legs.

Is there any influence of CNS in the development of scoliosis? In children with the Minimal Brain Dysfunction (MBD) or Attention Deficit Hyperactivity Disorder (ADHD) exist indirect influences:

a) Extension contracture of the trunk,

b) Anterior tilt of the pelvis,

c) "Laxity of the joints".

All these additions cause make easy oncoming scoliosis and enlarged the deformity.

What kind of therapy-conservative or operative-should be used in treatment?: Only conservative treatment is proper if we start in proper time, its mean in child's age 5-6 years. The proper therapy - are stretching exercise to receive full and symmetrical movement of hips and spine. Very beneficial exercise is all "Far East Sport Arts" like karate, taekwondo, aikido, kun fu.

Are extension exercises correct?: No-such exercises are wrong. They produce "iatrogenic deformity" - bigger curves, bigger rip hump, stiffer spine.

What kinds of rehabilitation exercises should be applied?: Only stretching exercises, giving the symmetry of movements and next the symmetry of the growth and development of the pelvis and the spine are proper. In the first instance, we should receive the "full symmetry of all movement of the hips" especially adduction in the straight position of the right hip joint. Next we should receive also the symmetry in "activity of the trunk muscles". For this aim are proper only stretching exercises.

The corset in treatment - yes or no?: I had to use the corset in 1995-2009 in 20\% of the children in the "S" $1^{\text {st }}$ epg scoliosis and in $5 \%-10 \%$ of the children in the "S" $2^{\text {nd }} / B$ epg scoliosis in children. Now - 2009 - 2019 - significantly less.

Is causative prophylaxis possible?: Yes - and should be introduced in all countries to all engendered children.

Important are:

a) Standing 'at ease' only on the left leg.

b) Stretching exercises to receiving of full adduction and internal rotation of the right hip.

c) Flexions exercises for spine - every day, many years, 
especially if appears the stiffness of the spine.

d) Sitting relax - never straight up.

e) Sleeping in embryo position with maximal flexed spine.

f) The children should make especially important and proper sport arts like karate, taekwondo, aikido, kung fu, yoga and other similarly.

\section{Conclusion}

1. In etiology of the so-called idiopathic scoliosis we must follow the research of Prof. Hans Mau's (Tübingen, Germany) about the "Syndrome of Contractures and Deformities (SofCD)"-Original in German "Siebenersyndrom".

2. The etiology is strictly biomechanical. The important role in oncoming of scoliosis play "gait" and "standing 'at ease' on the right leg".

3. There are three groups and four types of scoliosis:

a) "S" scoliosis - 3D - two curves, gibbous, stiff spine. Cause: gait and standing on the right leg.

b) 'C' scoliosis - 1D - one curve - lumbar left convex, flexible spine. Cause: standing on the right leg.

c) "S" scoliosis - 1D or 2D - two curves - flexible spine. Cause: standing on the right leg plus laxity.

d) "I" scoliosis - 2D or 3D - no curve or slight, no gibbous or minimal - stiff spine. Cause: gait.

4. In some children in etiology there are present additional causes such as:

a) Wrong and incorrect therapy / exercises,

b) Existing of primary extension contracture of the trunk, anterior tilt of pelvis and laxity of joints - symptoms of MBD.

c) Rickets.

d) Malformations of thorax - pectus infundibuliforme, pectus carinatum.

5. Causal prophylaxis is possible and very easy. Recommendations in points: a/ physiotherapy - kinesiotherapy for receiving full and symmetrical movement of hips and proper position of pelvis, b/ standing 'at ease' on the left leg, c/ sitting relax, d/ sleeping in embryo position, e/ performing sport - especially beneficial are - karate, taekwondo, aikido, kung fu, yoga.

\section{Acknowledgement}

I would like to express my many thanks to Honorata Menet for correction of the article.

\section{References}

1. Burwell G, Dangerfield PH, Lowe T, Margulies J (2000) Etiology of adolescent idiopathic scoliosis: Current trends and relevance to new treatment approaches. Spine 14(2): 324

2. Green NE, Griffin PP (1982) Hip dysplasia associated with abduction contracture of the contralateral hip. J Bone Joint Surg Am 64(9): 12731281.

3. Hensinger RN (1979) Congenital dislocation of the hip. Clinical Symp, pp. 31-37.

4. Howorth B (1977) The etiology of the congenital dislocation of the hip. Clin Orthop 29: 164-179.

5. Hyanek J. Personally information.

6. Karski T (2002) Etiology of the so-called "idiopathic scoliosis". Biomechanical explanation of spine deformity. Two 272 groups of development of scoliosis. New rehabilitation treatment. Possibility of prophylactics, Studies in 273 Technology and Informatics, Research into Spinal Deformities 4, IOS Press 2002, Amsterdam, Berlin, 274 Oxford, Tokyo, Washington DC, USA, 4: 37-46.

7. Karski T, Kalakucki J, Karski J (2006) "Syndrome of contractures" (according to Mau) with the abduction contracture of the right hip as causative factor for development of the so-called idiopathic scoliosis. Stud Health Technol Inform 123: 34.

8. Karski T (2010) Explanation of biomechanical etiology of the so-called idiopathic scoliosis (1995-2007). New 276 clinical and radiological classification in "Pohybove Ustroji" [Locomotor System] 17(1): 26-42.

9. Karski T (2011) Biomechanical etiology of the so-called idiopathic scoliosis (1995-2007) - Connection with 279 "syndrome of contractures"-fundamental information for paediatricians in program of early prophylactics/280. Journal of US-China Medical Science, USA, 8: 5.

10. Karski T (2010) Factores biomechanicos en la etiologia de las escoliosis dinominadas idiopaticas. Nueva 282 clasificacion. Nuevos test clinicos y nueavo tratamento conservador y profilaxis, Cuestiones de Fisioterapia, Mayo- 283 Agosto 39(2): 85-152.

11. Karski T (2010) Biomechanical etiology of the so-called idiopathic scoliosis (1995-2007). New classification: 285 Three groups, four sub-types. Connection with "Syndrome of Contractures", Pan Arab J Orth Trauma 14(2): 1-7.

12. Karski T (2013) Biomechanical etiology of the so-called idiopathic scoliosis (1995-2007). Three groups and 288 Four Types in the New Classification. Journal of Novel Physiotherapies, OMICS Publishing Group, USA, 2(6): 1-9.

13. Karski J, Tomasz K (2013) So-called idiopathic scoliosis. Diagnosis. Tests examples of children incorrect 291 treated. New therapy by stretching exercises and results. Journal of Novel Physiotherapies, OMICS Publishing 292 Group, 3-2(9): 1-8.

14. Karski T (2014) Biomechanical aetiology of the so-called idiopathic scoliosis. New classification (1995-2007) in connection with "Model of Hips Movements". Global Journal of Medical Research H: Orthopedic and Musculoskeletal System, 14(3): 1-9.

15. Karski T (2014) Biomechanical etiology of the so-called idiopathic scoliosis (1995-2007) - Connection with "Syndrome of Contractures"-Fundamental information for pediatricians in program of early prophylactics. Surgical Science 5: 33-38.

16. Karski T, Karski J (2015) "Syndrome of contractures and deformities" according to Prof. Hans Mau as primary cause of hip, neck, shank and spine deformities in babies, Youth and Adults. American Research Journal of Medicine and Surgery, 1(2): 9.

17. Karski T, Jacek K (2015) Biomechanical etiology of the so-called idiopathic scoliosis (1995-2007). Causative role of "gait" and "permanent standing 'at ease' pn the right leg". New classification. Principles of new therapy and causal prophylaxis. Canadian Open Medical Science \& Medicine Journal 1(1): 1-16.

18. Tomasz K, Jacek K (2016) Back pain - a neurological and orthopedic problem. Symptoms. Causes. Treatment. Back pain - neurology-orthopedic problems. Clinic, causes, therapy and prophylaxis. Advances in Practical Neurology, Czelej Publishing House, Poland, pp. 9-16. 
19. Karski J, Karski T (2016) "Imperfect hips" As a problem at an older age. Early and late prophylactic management before arthrosis. Jacobs Journal of Physiotherapy and Exercises, Texas, USA, 2(1): 015.

20. Karski T (2018) Biomechanical aetiology of the so-called Adolescent Idiopathic Scoliosis (AIS). Lublin classification (1995-2007). Causative influences connected with "Gait" and "Standing 'at ease' on the right leg". Journal of Orthopaedics and Bone Research, Scholarena, USA, p. 10.

21. Mau H (1979) Etiopathogenesis of scoliosis, hip dysplasia and torticollis of infancy. Journal of 294 orthoped 5: 601-605.

22. Mau H (1982) The atiopatogenesis of scoliosis, library of orthopedists. Enke Verlag Stuttgart 33: 1-296.
23. Mau H. Personal information and letter.

24. Normelly H (1985) Asymmetric rib growth as an aetiological factor in idiopathic scoliosis in adolescent girls. 298 Stockholm, pp. 1-103.

25. Stokes IAF (1999) Studies in technology and informatics, research into spinal deformities. IOS Press, USA, 29(2): 1-385.

26. Sevastik J, Diab K (1997) Studies in technology and informatics, research into spinal deformities. IOS 300 Press, USA, 37(1): 1-509.

27. Sevastik J. Personal information.

28. Thom H. Personal information.

29. www.ortopedia.karski.lublin.pl

For possible submissions Click below: 